\title{
Resilience, Family Functioning, and Psychological Well-Being: Findings from a Cross-sectional Survey of High-school Students
}

\author{
Mona Desrianty ${ }^{1}$, Norlizah C. Hassan ${ }^{1}$, Noor Syamilah Zakaria ${ }^{1}$, Zeinab Zaremohzzabieh ${ }^{1}$ \\ ${ }^{1}$ Faculty of Educational Studies, Universiti Putra Malaysia, Serdang, Selangor, Malaysia \\ Correspondence: Norlizah Che Hassan, Faculty of Educational Studies, Universiti Putra Malaysia, 43400 UPM \\ Serdang, Selangor, Malaysia. Tel: 603-9769-8210. E-mail: norlizah@upm.edu.my
}

Received: September 3, 2021

Accepted: September 28, 2021 Online Published: October 14, 2021

doi:10.5539/ass.v17n11p77

URL: https://doi.org/10.5539/ass.v17n11p77

\begin{abstract}
The present study examined the relationship between family functioning and resilience on the psychological well-being (PWB) in high school students. A cross-sectional study was conducted using multiple linear regression for prediction and descriptive statistical analysis in five Indonesian high school students. A total of 341 high school students participated in the study, completing three validated self-administered questionnaires. Statistical analysis revealed that greater family functioning was associated with higher PWB. A significant relationship between resilience and PWB was found in this cohort. This study showed that to maintain healthy mental well-being, developing resilience and family functioning is vital for high school students. More emphasis may be placed on the possible role of resilience training and other kinds of family functioning and coping strategies in dealing with the unavoidable causes of stress in public high schoolers.
\end{abstract}

Keywords: Family Functioning, Resilience, Psychological Well-Being, Public High School Students

\section{Introduction}

Stress has been established as a disease of the twentieth century, and it has been intensively researched in school students (Pascoe et al., 2020; van Loon et al., 2020). To date, many researchers suggest that school students are under a lot of stress, especially at the beginning and end of their academic year (e.g., Brown, 2007). Excessive stress can lead to anxiety and depression, as well as a decline in academic performance (Maajida Aafreen et al., 2018). Maintaining excellent levels of psychological well-being (PWB) is essential in students' high school development years (Bendixen et al., 2018; Fomina et al., 2020). However, the PWB of high schoolers is negatively impacted by poor focus, heightened anxiety levels, chronic depression, and sleep disorders (Calderon Jr et al., 2021; Zaremohzzabieh et al., 2019). Thus, it is essential to make an effort to maintain and improve the PWB among high school students.

Many scholars have analyzed the PWB paradigm with a variety of constructs, including resilience and family functioning. Resilience is one's ability to not only endure challenging conditions without relent but to press on through life stressors (Polizzi et al., 2020). According to Srivastava (2011), resilience boosts one's well-being which means conversely, lower resilience leads to negative mental health outcomes (DeRosier et al., 2013; Qi et al., 2021). In a sample of 224 mid-to-late adolescents, researchers reported the positive association of PWB (environmental mastery, personal growth, and self-acceptance) with resilience (Sagone \& De Caroli, 2014). Another study found that resilience predicts a healthy psychological state with partial mediation between emotional intelligence and PWB of high school students (Akbari \& Khormaiee, 2015). Picardi et al. (2012) observed a possible positive correlation between PWB and dispositional resilience (commitment, control, and challenge), except for the dimension of autonomy. In a sample of university students during the peri-traumatic phase of COVID-19, researchers found that resilience predicted PWB, both directly and indirectly (Sood \& Sharma, 2021).

Family functioning is also a PWB predictor among students (Shek, 2005). Several researchers highlighted that family functioning is an important piece of a puzzle when it comes to seeking a deeper understanding of adolescent mental health problems and well-being (Milburn et al., 2019). In essence, family functioning is the integration of various family characteristics where the family unit is a system by itself, and this perspective allows the examination of its overall functional role. Accordingly, the level of family functioning indicates the operational health of an individual's family system which closely affects adolescents' mental state (Shek, 2005). 
The theory of psychological suzhi states that the individuals' interactions with their proximal environments form sushi (Zhang \& Wang, 2020). Given this, family, as the most direct and recent micro-environment, will significantly impact students' sushi development, which in turn impacts their state of mental health (Zeleke, 2013). Unsurprisingly, several scholars have highlighted the importance of paying attention to the key role of family functioning when investigating adolescent psychological problems (Milburn et al., 2019). Furthermore, a recent study has determined family functioning as an important environmental factor that moderates the link between school, well-being, and mental health (Albanese et al., 2019). Sari and Dahlia (2018) found that family functioning was significantly related to subjective well-being among adolescents with $r$ value $=0.167(p<0.05)$. Therefore, some researchers advocated that for holistic individual development, it is more beneficial for the individual to receive intervention from multiple factors instead of only one, which is more practical (Luthans et al., 2006; Pervanidou et al., 2019). According to the theory of the developmental system, schools and families, although mutually exclusive on youth development, are bound by robust interaction and connection (Lakind et al., 2015).

In addition, Ryff's PWB model could be applied to school-going children because it possesses high levels of each six dimensions, and this represents the important steps required during an optimal developmental process. Therefore, building resiliency and family functioning in the school setting is critical for the mental well-being of high schoolers. However, to the best of our knowledge, little research has directly investigated the effects of family functioning and resiliency on high schoolers' PWB. Numerous PWB researchers highlighted that studies in a school context have not gained urgent attention, which they should (Musick et al., n.d.; Nomaguchi, 2012). Therefore, this study seeks to examine the relationships between family functioning and resiliency, and PWB among public high schoolers. This study hypothesized that (a) resiliency has a positive relationship with PWB, and (b) family functioning has a positive relationship with the PWB of high school students.

\section{Materials and Methods}

This cross-sectional study is used to provide helpful information regarding the relationship between family functioning and resilience on high school students' psychological well-being (PWB). A cluster random sampling was adopted. A sample of high school students was selected from Public High School in Siak Sri Indrapura district, Riau, Indonesia. The district has 14 Public Senior High schools owned by the government or receiving supports from the government. The total number of students in the Siak Sri Indrapura district is 2946 students in 2019. Because the overall population in this study is greater than 1000 high school students, the Cochran formula is employed to select a sample. After calculation, 341 students make up the total number of samples in this study. The sample selection in this study is conducted through cluster random sampling. In this study, the names of 13 schools in the Siak district (excluding one school for pilot study) are written on a piece of paper, then, a school is selected randomly. The total number of students in the selected school is computed, if the number does not fulfill the minimum sample size, the next school is selected from the pool of school names. This method is repeated until the minimum number of samples is fulfilled. The schools selected in this study are SMAN 1 Koto Gasib (68 students), SMAN 1 Sabah Auh (68 students), SMAN 1 Sungai Apit (69 students), and SMAN 1 Dayun (68 students). The final sample included 341 high schoolers, where 152 were males and 189 were females. The response rate was about $100 \%$.

Three scales were used to measure the variables in this study: (1) the Family Assessment Device (Epstein et al., 1983) to measure family functioning; (2) the Resilience Scale (Wagnild \& Young, 1990); and (3) the Psychological Well-being Scale (Ryff, 1989). The Family Assessment Device, the Resilience Scale, and the Psychological Well-being Scale have been confirmed to yield high internal consistency with Cronbach's alpha coefficient 0.75, 0.88, and 0.89 respectively. Each instrument had the 5-points Likert Scale for scoring.

Before the main research being undertaken, UPM Ethics Committee for a study that involving human subjects (JKEUPM) approved the procedure of doing the study. This is to ensure that all principles and ethical steps have been fulfilled during the research and subject's rights or human subjects are protected. Besides that, before collecting data for pilot tests and real study, the researcher also submits an application for a research permit to the Headmaster of schools in Siak district and the head of the Education Office of Siak district. All documents needed are attached and sent to the website. After the research permit is granted, the pilot test was conducted with 30 students to validate the questionnaires and clarify question-wording. According to the findings of the pilot research, all three scales were internally consistent, with alphas ranging from 0.71 to 0.95 .

For data analysis, this study employed descriptive and inferential statistics. Means and standard deviations were used to describe the three constructs. To determine the predictors, multiple linear regression techniques were used. Therefore, by using this analysis, the researcher can determine whether resilience and family functioning 
are the best predictors of PWB.

\section{Results}

Table 1 presents the descriptive statistics for the three latent constructs. The results indicate that respondents' PWB perception is well above average $(\mathrm{M}=4.123, \mathrm{SD}=.508)$ and resilience even appears to be lower $(\mathrm{M}=$ $3.010, \mathrm{SD}=.328)$. It was also found that on average, family functioning is low $(\mathrm{M}=2.746, \mathrm{SD}=.232)$. The results of this study indicated that skewness ranged from -.127 to -.160 and kurtosis ranged from -.177 to 1.953 , in which all items were considered to be normal.

Table 1. Descriptive statistics, construct reliability, AVE estimates, and squared correlation coefficients

\begin{tabular}{cccccc}
\hline Constructs & Mean & SD & $\alpha$ & 1 & 2 \\
\hline 1. PSW & 4.123 & .508 & 0.88 & & \\
2. FF & 2.746 & .232 & 0.72 & $565^{* *}$ & \\
3. RE & 3.010 & .328 & 0.87 & $.389^{* *}$ & $.432^{* *}$ \\
\hline
\end{tabular}

Note. PSW=Psychological well-being, Family functioning=FF, Resilience=RE, $\alpha=$ construct reliability value

Table 2. Beta value for psychological well-being

\begin{tabular}{cccccc}
\hline Model & Unstandardized Coefficient, B & Std. Error & Standardized Coefficient, $\beta$ & $\mathrm{t}$ & $\mathrm{p}$ \\
\hline Constant & -.342 & .296 & - & -1.158 & .248 \\
FF & .1 .122 & .093 & .512 & 12.019 & .000 \\
RE & .460 & .066 & .298 & 6.988 & .000 \\
\hline
\end{tabular}

Note. Family functioning=FF, Resilience=RE, $\mathrm{R}^{2}=.401, \mathrm{~F}(2,339)=115.220, \mathrm{p}<0.001$.

The findings show that the path coefficients in the direct model indicate that family functioning $(\beta=0.512$, $\mathrm{p}<0.001)$ are significantly related to PWB, and this supports Hypothesis 1 and satisfying the direct effect condition. Resilience $(\beta=.298, \mathrm{p}<0.001)$ is significantly related to PWB, and this supports Hypothesis 2 . Family functioning and resilience jointly explained $40.1 \%\left(\mathrm{R}^{2}=.401\right)$ of the variance in PWB (Table 2).

\section{Discussion}

PWB is vital at high school because high schools play an important role in helping students to make healthy lifestyle decisions. Thus, the overarching purpose of this research was to predict Indonesian high schoolers' PWB based on resilience and family functioning. The results indicate that PWB is positively and significantly correlated to resilience. Consistent with the findings of past studies, researchers observed that when students' resilience level is high and are less stressed, they enjoy improved PWB (García-Izquierdo et al., 2018; Klainin-Yobas et al., 2014; Ríos-Risquez et al., 2016; Smith \& Yang, 2017). Also, the findings indicated the presence of high interaction between resilience and PWB while resilience was observed as a better PWB predictor. The results were supported by previous findings (Qi et al., 2021; Quintiliani et al., 2021). Therefore, it can be posited that resilience is either a consequential and/or an influencer of improved PWB outcomes. The study can see this subject's resilience from the point of the intricacy of the definition and processing view to resilience and psychological well-being. As factors and capacities, resilience and PWB are deemed unstable. Rather, their dynamistic nature allows personality traits to enhance resilience and vice versa.

Based on the findings, the results also show that there are significantly strong correlations between family functioning and PWB among SMAN students at Siak Sri Indrapura. Therefore, to improve a student's PWB, it is crucial to get into the heart of the quality of family functioning as the predictor of a student's well-being, especially during the adolescent stage (Pan et al., 2021; Sari \& Dahlia, 2018; Shek, 2005). This finding is supported by the resilience literature that observed positive family functioning leading towards student's PWB (Chow, 2010; Mason, 2016; Shek, 2005; Tulk et al., 2016). This study also discovered that family functioning has a link to maintaining one's mental health. A person may bear much more pain and be able to adapt with the help of their closest family members who frequently interact with each other, perform their position in the family correctly, effectively involve and are responsive to their family members, and have a strong problem-solving talent in the family. 


\section{Conclusion and Recommendation}

In conclusion, the results contribute to the educational psychology literature by providing additional empirical support for the capacity of the two constructs (i.e., resiliency and family functioning) in predicting the psychological well-being of Indonesian high school students. With a keen focus on the relationship between resilience and PWB, school counselors may benefit from the new insights of this study as they aid students with stress coping strategies, adapting, and enjoying their schooling years. Thinking agility should be taught to students as they navigate through school and life stressors and challenges. Through training programs, students can learn their resiliency potentials and how to enhance them, thus boosting academic performance. Most importantly, the studies recommend that stakeholders should pay greater attention to high schoolers by equipping them with resilience coping skills. Meanwhile, school counselors should occasionally monitor students' resilience and family functioning to help them maintain their well-being. Similarly, the Ministry of Education of Indonesia (MoE), as a government institution, should focus on developing students' well-being as the foundation for mental health and academic performance. Therefore, the MoE should spearhead more programs and activities to build students' resilience and family functioning. The limitation of this study arises from the design of this study which is a cross-sectional study. The limitation of this study arises when having adopted a cross-sectional design in this study, a future study employing a different research design would be interesting. This will provide an in-depth understanding of the said variables. More broadly, future country comparison studies are also needed to examine the interactive behaviors of these variables in high schoolers in an international context.

\section{References}

Akbari, A., \& Khormaiee, F. (2015). The prediction of the mediating role of resilience between psychological well-being and emotional intelligence in students. International Journal of School Health, 2(3), 1-5. https://doi.org/10.17795/intjsh-26238

Albanese, A. M., Russo, G. R., \& Geller, P. A. (2019). The role of parental self-efficacy in parent and child well-being: A systematic review of associated outcomes. Child: Care, Health and Development, 45(3), 333-363. https://doi.org/10.1111/cch.12661

Bendixen, M., Daveronis, J., \& Kennair, L. E. O. (2018). The effects of non-physical peer sexual harassment on high school students' psychological well-being in Norway: Consistent and stable findings across studies. International Journal of Public Health, 63(1), 3-11. https://doi.org/10.1007/s00038-017-1049-3

Brown, T. M. (2007). Lost and turned out: Academic, social, and emotional experiences of students excluded from school. Urban Education, 42(5), 432-455. https://doi.org/10.1177/0042085907304947

Byrne, B. (2016). Structural equation modeling with AMOS: Basic concepts, applications, and programming. Routledge. https://doi.org/10.4324/9781315757421

Calderon Jr, R., Pupanead, S., Prachakul, W., \& Kim, G. (2021). Happiness, perceived stress, psychological well-being, and health behaviors of Thai university students: Preliminary results from a multinational study on well-being. Journal of American College Health, 69(2), 176-184. https://doi.org/10.1080/07448481.2019.1657871

Cheung, R. Y. M., Leung, M. C., Chiu, H. T., Kwan, J. L. Y., Yee, L. T. S., \& Hou, W. K. (2019). Family functioning and psychological outcomes in emerging adulthood: Savoring positive experiences as a mediating mechanism. Journal of Social and Personal Relationships, 36(9), 2693-2713. https://doi.org/10.1177/0265407518798499

Chow, H. P. (2010). Predicting academic success and psychological wellness in a sample of Canadian undergraduate students. Electronic Journal of Research in Educational Psychology, 8(2), 473-496.

DeRosier, M. E., Frank, E., Schwartz, V., \& Leary, K. A. (2013). The potential role of resilience education for preventing mental health problems for college students. Psychiatric Annals, 43(12), 538-544. https://doi.org/10.3928/00485713-20131206-05

Epstein, N. B., Baldwin, L. M., \& Bishop, D. S. (1983). The McMaster Family Assessment Device. Journal of Marital and Family Therapy, 9(2), 171-180. https://doi.org/10.1111/j.1752-0606.1983.tb01497.x

Fomina, T., Burmistrova-Savenkova, A., \& Morosanova, V. (2020). Self-regulation and psychological well-being in early adolescence: A two-wave longitudinal study. Behavioral Sciences, 10(3), 67. https://doi.org/10.3390/bs10030067

García-Izquierdo, M., Meseguer de Pedro, M., Ríos-Risquez, M. I., \& Sánchez, M. I. S. (2018). Resilience as a moderator of psychological health in situations of chronic stress (burnout) in a sample of hospital nurses. 
Journal of Nursing Scholarship, 50(2), 228-236. https://doi.org/10.1111/jnu.12367

Geerts-Perry, A. T., Riggs, S. A., Kaminski, P. L., \& Murrell, A. (2021). Psychological Well-Being and Family Functioning in Middle Childhood: The Unique Role of Sibling Relational Dynamics. Journal of Family Issues. https://doi.org/10.1177/0192513X21993191

Hair, J., Black, W., Babin, B., \& Anderson, R. (2010). Multivariate data analysis. Prentice Hall.

Huffman, E. M., Athanasiadis, D. I., Anton, N. E., Haskett, L. A., Doster, D. L., Stefanidis, D., \& Lee, N. K. (2021). How resilient is your team? Exploring healthcare providers' well-being during the COVID-19 pandemic. The American Journal of Surgery, 221(2), 277-284. https://doi.org/10.1016/j.amjsurg.2020.09.005

Klainin-Yobas, P., Keawkerd, O., Pumpuang, W., Thunyadee, C., Thanoi, W., \& He, H.-G. (2014). The mediating effects of coping on the stress and health relationships among nursing students: A structural equation modelling approach. JAN: Leading Global Nursing Reaearch, 70(6), 1287-1298. https://doi.org/10.1111/jan.12283

Lakind, D., Atkins, M., \& Eddy, J. M. (2015). Youth mentoring relationships in context: Mentor perceptions of youth, environment, and the mentor role. Children and Youth Services Review, 53, 52-60. https://doi.org/10.1016/j.childyouth.2015.03.007

Luthans, F., Vogelgesang, G. R., \& Lester, P. B. (2006). Developing the psychological capital of resiliency. Human Resource Development Review, 5(1), 25-44. https://doi.org/10.1177/1534484305285335

Maajida Aafreen, M., Vishnu Priya, V., \& Gayathri, R. (2018). Effect of stress on academic performance of students in different streams. Drug Invention Today, 10(9), 1776-1780.

Mason, H. (2016). Multiple measures of family and social support as predictors of psychological well-being: An additive approach. Journal of Educational and Developmental Psychology, 6(2), 97-112. https://doi.org/10.5539/jedp.v6n2p97

Milburn, N. G., Stein, J. A., Lopez, S. A., Hilberg, A. M., Veprinsky, A., Arnold, E. M., ... Bath, E. (2019). Trauma, family factors and the mental health of homeless adolescents. Journal of Child \& Adolescent Trauma, 12(1), 37-47. https://doi.org/10.1007/s40653-017-0157-9

Musick, K., Meier, A., \& Flood, S. (n.d.). How Parents Fare: Mothers' and Fathers' Subjective Well-Being in Time with Children. American Sociological Review, 81(5), 1069-1095. https://doi.org/10.1177/0003122416663917

Nomaguchi, K. M. (2012). Parenthood and psychological well-being: Clarifying the role of child age and parentchild relationship quality. Social Science Research, 41(2), 489-498. https://doi.org/10.1016/j.ssresearch.2011.08.001

Pan, Y., Yang, Z., Han, X., \& Qi, S. (2021). Family functioning and mental health among secondary vocational students during the COVID-19 epidemic: A moderated mediation model. Personality and Individual Differences, 171, 110490. https://doi.org/10.1016/j.paid.2020.110490

Pascoe, M. C., Hetrick, S. E., \& Parker, A. G. (2020). The impact of stress on students in secondary school and higher education. International Journal of Adolescence and Youth, 25(1), 104-112. https://doi.org/10.1080/02673843.2019.1596823

Pervanidou, P., Makris, G., Bouzios, I., Chrousos, G., Roma, E., \& Chouliaras, G. (2019). Bullying victimization: Associated contextual factors in a Greek sample of children and adolescents. Psychiatrike $=$ Psychiatriki, 30(3), 216-225. https://doi.org/10.22365/jpsych.2019.303.216

Picardi, A., Bartone, P. T., Querci, R., Bitetti, D., Tarsitani, L., Roselli, V., ... Gaviano, I. (2012). Development and validation of the Italian version of the 15-item dispositional resilience scale. Rivista Di Psichiatria, 47(3), 231-237. https://doi.org/10.1037/t69210-000

Polizzi, C., Lynn, S. J., \& Perry, A. (2020). Stress and coping in the time of COVID-19: Pathways to resilience and recovery. Clinical Neuropsychiatry, 17(2), 59-62.

Qi, L. Y., Roslan, S., \& Zaremohzzabieh, Z. (2021). Perceived Social Support and Psychological Well-Being of International Students: The Mediating Effects of Resiliency and Spirituality. Asian Journal of University Education, 17(3), 220-234. https://doi.org/10.1080/13548506.2021.1891266

Quintiliani, L., Sisto, A., Vicinanza, F., Curcio, G., \& Tambone, V. (2021). Resilience and psychological impact 
on Italian university students during COVID-19 pandemic. Distance learning and health. Psychology, Health \& Medicine, in press, 1-12.

Ríos-Risquez, M. I., García-Izquierdo, M., de los Angeles Sabuco-Tebar, E., Carrillo-Garcia, C., \& Martinez-Roche, M. E. (2016). An exploratory study of the relationship between resilience, academic burnout and psychological health in nursing students. Contemporary Nurse, 52(4), 430-439. https://doi.org/10.1080/10376178.2016.1213648

Ryff, C. D. (1989). Happiness is everything, or is it? Explorations on the meaning of psychological well-being. Journal of Personality and Social Psychology, 57(6), 1069-1081. https://doi.org/10.1037/0022-3514.57.6.1069

Sagone, E., \& De Caroli, M. E. (2014). Relationships between psychological well-being and resilience in middle and late adolescents. Procedia-Social and Behavioral Sciences, 141, 881-887. https://doi.org/10.1016/j.sbspro.2014.05.154

Sari, E. P., \& Dahlia, W. (2018). Family functioning and subjective well-being among adolescents. MOJPC: Malaysia Online Journal of Psychology \& Counselling, 5(1), 43-51.

Shek, D. T. (2005). Perceived parental control processes, parent - Child relational qualities, and psychological well-being in Chinese adolescents with and without economic disadvantage. The Journal of Genetic Psychology, 166(2), 171-188. https://doi.org/10.3200/GNTP.166.2.171-188

Smith, G. D., \& Yang, F. (2017). Stress, resilience and psychological well-being in Chinese undergraduate nursing students. Nurse Education Today, 49, 90-95. https://doi.org/10.1016/j.nedt.2016.10.004

Sood, S., \& Sharma, A. (2021). Resilience and Psychological Well-Being of Higher Education Students During COVID-19: The Mediating Role of Perceived Distress. Journal of Health Management, 22(4), 606-617. https://doi.org/10.1177/0972063420983111

Srivastava, K. (2011). Positive mental health and its relationship with resilience. Industrial Psychiatry Journal, 20(2), 75-76. https://doi.org/10.4103/0972-6748.102469

Tabachnick, B. G., \& Fidell, L. S. (2013). Using multivariate statistics (International edition). Pearson.

Tulk, L., Montreuil, S., Pierce, T., \& Pépin, M. (2016). Does parental work affect the psychological well-being and educational success of adolescents? Community, Work \& Family, 19(1), 80-102. https://doi.org/10.1080/13668803.2014.1002830

van Loon, A. W., Creemers, H. E., Beumer, W. Y., Okorn, A., Vogelaar, S., Saab, N., ... Asscher, J. J. (2020). Can schools reduce adolescent psychological stress? A multilevel meta-analysis of the effectiveness of school-based intervention programs. Journal of Youth and Adolescence, 49(6), 1127-1145. https://doi.org/10.1007/s10964-020-01201-5

Wagnild, G., \& Young, H. M. (1990). Resilience Among Older Women. Image: The Journal of Nursing Scholarship, 22(4), 252-255. https://doi.org/10.1111/j.1547-5069.1990.tb00224.x

Zaremohzzabieh, Z., Samah, A. A., Samah, B. A., \& Shaffril, H. A. M. (2019). Determinants of happiness among youth in Malaysia. International Journal of Happiness and Development, 5(4), 352-370. https://doi.org/10.1504/IJHD.2019.104370

Zeleke, W. A. (2013). Psychological adjustment and relational development in Ethiopian adoptees and their families [PhD Thesis]. University of Montana.

Zhang, T., \& Wang, Z. (2020). The Effects of Family Functioning and Psychological Suzhi Between School Climate and Problem Behaviors. Frontiers in Psychology, 11, 1-9. https://doi.org/10.3389/fpsyg.2020.00212

\section{Copyrights}

Copyright for this article is retained by the author(s), with first publication rights granted to the journal.

This is an open-access article distributed under the terms and conditions of the Creative Commons Attribution license (http://creativecommons.org/licenses/by/4.0/). 